\title{
Acute conduction velocity changes in guinea-pigs after administration of diphenylhydantoin
}

\author{
PAMELA M. LE QUESNE, VALERIE GOLDBERG, AND F. VAJDA \\ From the Medical Research Council Toxicology Unit, Carshalton, Surrey; \\ the Department of Neurological Studies and the Department of Pharmacology, \\ The Middlesex Hospital, London; and the Department of Chemical Pathology, \\ Institute of Neurology, Queen Square, London
}

SYNOPSIS Motor nerve conduction velocity was measured after dosing guinea-pigs with 200$400 \mu \mathrm{mol} / \mathrm{kg}$ diphenylhydantoin (DPH) daily for three to four days. Conduction velocity fell by a mean value of $13 \%$ in animals that achieved plasma DPH levels over $200 \mu \mathrm{mol} / \mathrm{l}$. There was no change in velocity with DPH levels below this value.

Diphenylhydantoin (DPH) may produce mild peripheral neuropathy in patients who have received the drug for several years (Lovelace and Horwitz, 1968; Eisen et al., 1974; Chokroverty and Sayeed, 1975). Lower limb areflexia, loss of vibration sensation, and occasional slight disturbances of other sensory modalities occur. The motor system is rarely involved and never severely. The incidence of abnormal signs appears to be related to the duration of therapy, rather than to the dose taken. Thus, in 50 unselected patients, Lovelace and Horwitz (1968) found that lower limb reflexes were absent in $18 \%$ of patients treated for more than five years, but in $50 \%$ of those treated for more than 15 years. Chokroverty and Sayeed (1975) examined 35 patients on DPH therapy. Three had absent reflexes and all three had been treated for more than 10 years. Some reduction in nerve conduction velocity has also been demonstrated in patients receiving the drug for many years, even without abnormal signs (Lovelace and Horwitz, 1968; DeCastro et al., 1972; Eisen et al., 1974; Encinoza, 1974; Chokroverty and Sayeed, 1975).

In distinction from a mild chronic effect on peripheral nerve function after exposure to DPH for many years, the drug appears to have an acute effect on conduction velocity when given in high doses. When intravenous DPH was given to rabbits Morrell et al. (1958) found some increase in conduction time

(Accepted 14 May 1976.) in the posterior tibial nerve, as well as effects on other parameters of nerve excitability. In man, Hopf (1968) found that after treatment for 11 days there was an increase in the range of conduction velocity in the ulnar nerve. There was no effect on maximal velocity, thus suggesting that the smaller and slower conducting fibres were more affected. Birkett-Smith and Krogh (1971) measured motor nerve conduction velocity in a series of patients with high DPH levels in the serum and repeated the estimation about a week later, when the serum level had fallen after reduction in the dose. In patients with initial DPH concentrations above $30 \mathrm{mg} / \mathrm{l}(120 \mu \mathrm{mol} / \mathrm{l})$ maximal nerve conduction velocity was reduced and when the measurement was repeated the velocity had increased in all. The increase ranged from 0.9 to $14.3 \mathrm{~m} / \mathrm{s}$. The mean percentage increase in velocity was $13.7 \%$. When the DPH levels had fallen to less than $30 \mathrm{mg} / \mathrm{l}$ $(120 \mu \mathrm{mol} / \mathrm{l})$ conduction velocities were similar to control values. Chokroverty and Sayeed (1975) also found a slight reduction of conduction velocity in patients with serum DPH levels above $20 \mathrm{mg} / \mathrm{l}$ $(80 \mu \mathrm{mol} / \mathrm{l})$ when they examined an unselected group of 35 patients. They suggest that DPH appears to have an acute reversible effect and also a long-term effect on peripheral nerves.

In order to investigate the acute effect of DPH on nerve conduction velocity, a group of guinea-pigs was given DPH for three or four days orally in varying doses and changes in conduction velocity estimated. The results were correlated with plasma DPH concentrations. 


\section{METHODS}

White Dunkin-Hartley guinea-pigs were used. All animals were aged more than 6 months, by which age motor nerve conduction velocity would be expected to have reached the adult range (Fullerton, 1966).

Maximum motor nerve conduction velocity was measured in the fibres supplying the small muscles on the plantar surface of the hind limb, using the technique described by Fullerton (1966). Animals were anaesthetised with intraperitoneal pentobarbitone, supplemented, when necessary, by fluothane given with oxygen through a facial mask. Supramaximal shocks were applied to the sciatic nerve in the upper thigh and to the posterior tibial nerve at the ankle. Muscle action potentials were recorded through subcutaneous needle electrodes, one over the middle of the bellies of the interosseous muscles and the other beside the tendon of the lateral toe. Limb temperature was maintained by laying the animals on a heated operating table and by radiant heat from a lamp. Care in maintaining limb temperature was particularly important in ill animals. Subcutaneous thigh temperature was always $36^{\circ} \mathrm{C}-$ $38^{\circ} \mathrm{C}$.

In 18 control animals conduction velocity was measured on two occasions at intervals of three days to four weeks. This gave an indication of the range of variation to be expected in repeated estimations using this technique. In 38 animals conduction velocity was measured before and after dosing with DPH.

Diphenylhydantoin sodium was administered orally by stomach tube. Material from capsules of diphenylhydantoin (Parke Davies) was suspended in methyl cellulose 2500 gel $2 \%$ (diluted to a final concentration of $0.5 \%$ ) to give a DPH concentration in the suspension of $100 \mathrm{mmol} / \mathrm{l}$. DPH was given in doses ranging from $200-400 \mu \mathrm{mol} / \mathrm{kg} /$ day (Table 1 ).
These doses are considerably higher than those given therapeutically to man, but were used in an attempt to achieve plasma concentrations in the range known to be toxic to man.

In the majority of animals conduction velocity was measured three hours after the last dose, and $2 \mathrm{ml}$ blood were then taken by cardiac puncture. In some severely ill animals conduction velocity was measured 24 hours after dosing, as they were considered to be too ill to receive a further dose on the day conduction velocity was estimated. In four animals who survived and who achieved high plasma DPH levels (over $200 \mu \mathrm{mol} / \mathrm{l}$ ), conduction velocity was measured again between one and three weeks later, during which time no further DPH was given.

DPH levels were estimated on heparinised samples of blood either by a modification of the gas liquid chromatographic method of MacGee (1970) as described by Vajda et al. (1974), or by a combination of the extraction method of Toseland et al. (1972) and the GLC method of MacGee (1970), as described by Goldberg et al. (1974). These methods are widely accepted as specific, accurate, and reproducible (Meijer et al., 1973; Eadie and Tyrer, 1974). The coefficient of variation is $2 \%$ and recovery is approximately $98 \%$.

\section{RESULTS}

Table 1 shows details of the experimental animals, dosage schedules of DPH and plasma DPH levels achieved in different groups of animals. Twenty-eight animals were given 200 or $240 \mu \mathrm{mol} / \mathrm{kg}$ DPH daily for four days. Although, as might be expected, there was considerable variation in plasma DPH level achieved by individual animals, there was little difference in mean levels or in the range of values achieved with these two dose levels. Two animals in this group developed severe respiratory infection and died

T A B L E 1

DETAILS OF EXPERIMENTAL ANIMALS, DOSAGE SCHEDUles OF DPH, AND PLASMA DPH LEVELS ACHIEVED

\begin{tabular}{|c|c|c|c|c|c|c|}
\hline \multirow[b]{2}{*}{$\begin{array}{c}\text { Animals } \\
\text { (no.) }\end{array}$} & \multirow[b]{2}{*}{$\begin{array}{l}\text { Daily dose } \\
(\mu \mathrm{mol} / \mathrm{kg})\end{array}$} & \multirow[b]{2}{*}{$\begin{array}{c}\text { Doses } \\
\text { (no.) }\end{array}$} & \multirow[b]{2}{*}{$\begin{array}{c}\text { Animals clinically } \\
\text { affected } \\
\text { (no.) }\end{array}$} & \multirow[b]{2}{*}{$\begin{array}{l}\text { Interval between } \\
\text { last dose and blood } \\
\text { samples in hours } \\
(\text { no. of animals })\end{array}$} & \multicolumn{2}{|c|}{ Plasına DPH $(\mu \mathrm{mol} / \mathrm{l})$} \\
\hline & & & & & Mean & Range \\
\hline 6 & 200 & 4 & 0 & 3 & 136 & $88-220$ \\
\hline 22 & 240 & 4 & 2 & 3 & 144 & $68-232$ \\
\hline 5 & 300 & 2 or 3 & 3 & $3(3)$ & 204 & $184-216$ \\
\hline & & & & $24(2)$ & 184 & $112-252$ \\
\hline 5 & 400 & 2 or 3 & 5 & 24 & 260 & $188-344$ \\
\hline
\end{tabular}


shortly after conduction velocity was measured. Several other animals from the same batch developed a similar illness, although untreated. It thus seemed that the illness was unrelated to DPH administration. All the other animals remained healthy, with no loss of weight. Their general appearance, vigour, and gait appeared normal.

Of the animals given higher doses ( 300 and 400 $\mu \mathrm{mol} / \mathrm{kg} /$ day), all except two were clinically affected. Several animals died before conduction velocity could be measured on the fourth day and so in other animals measurements were made after only two or three doses. Affected animals lost weight and became sluggish. They staggered on attempted movement. Severely affected animals were unable to stand and lay with frequent fine tremors of the limbs.

Figure 1 shows the results of maximal motor nerve conduction velocity determination. The control group consists of animals in whom conduction velocity was estimated on two occasions at intervals of three days to four weeks. The mean value for the first reading was $52 \mathrm{~m} / \mathrm{s}$ and for the second reading was $51 \mathrm{~m} / \mathrm{s}$. The animals treated with DPH were divided into three groups on the basis of the plasma DPH levels achieved; less than $120 \mu \mathrm{mol} / 1,120-200 \mu \mathrm{mol} / 1$, and above $200 \mu \mathrm{mol} / \mathrm{l}$. In all animals conduction velocity was measured before and after dosing.

The paired $t$ test was used to compare the first and second estimations of conduction velocity (Table 2 ).
The difference between the first and second reading was significant only in the group of animals with DPH levels over $200 \mu \mathrm{mol} / \mathrm{l}$, in which the mean value fell from $53 \mathrm{~m} / \mathrm{s}$ before dosing to $46 \mathrm{~m} / \mathrm{s} \quad(\mathrm{P}<0.001)$ after dosing.

Percentage change in conduction velocity between the first and second estimations is shown in relation to the plasma DPH concentration achieved in Fig. 2. It can be seen that in animals that had achieved levels of less than $200 \mu \mathrm{mol} / \mathrm{l}$ there was little effect on conduction. In animals with levels above this value, conduction velocity fell in all.

Percentage change in conduction velocity is shown for the different groups of animals in Fig. 3 and Table 2. In the control animals values ranged from -18 to $+16 \%$ (mean $-1 \pm 8.9 \%$ ). It can be seen that, in the group of animals with DPH concentrations above $200 \mu \mathrm{mol} / \mathrm{l}$, conduction velocity was less after dosing in all, whereas results in the other groups were very similar to those obtained in unintoxicated animals. The percentage change in velocity for the different intoxicated groups was compared with the percentage change in control animals using the $t$ test. The difference was significant only in the group with DPH levels over $200 \mu \mathrm{mol} / 1 \quad(\mathrm{P}<0.005)$. The mean reduction in velocity for this group was $13 \%$.

Four animals which had achieved plasma DPH levels over $200 \mu \mathrm{mol} / \mathrm{l}$ survived and, after no further DPH was given, conduction velocity was measured

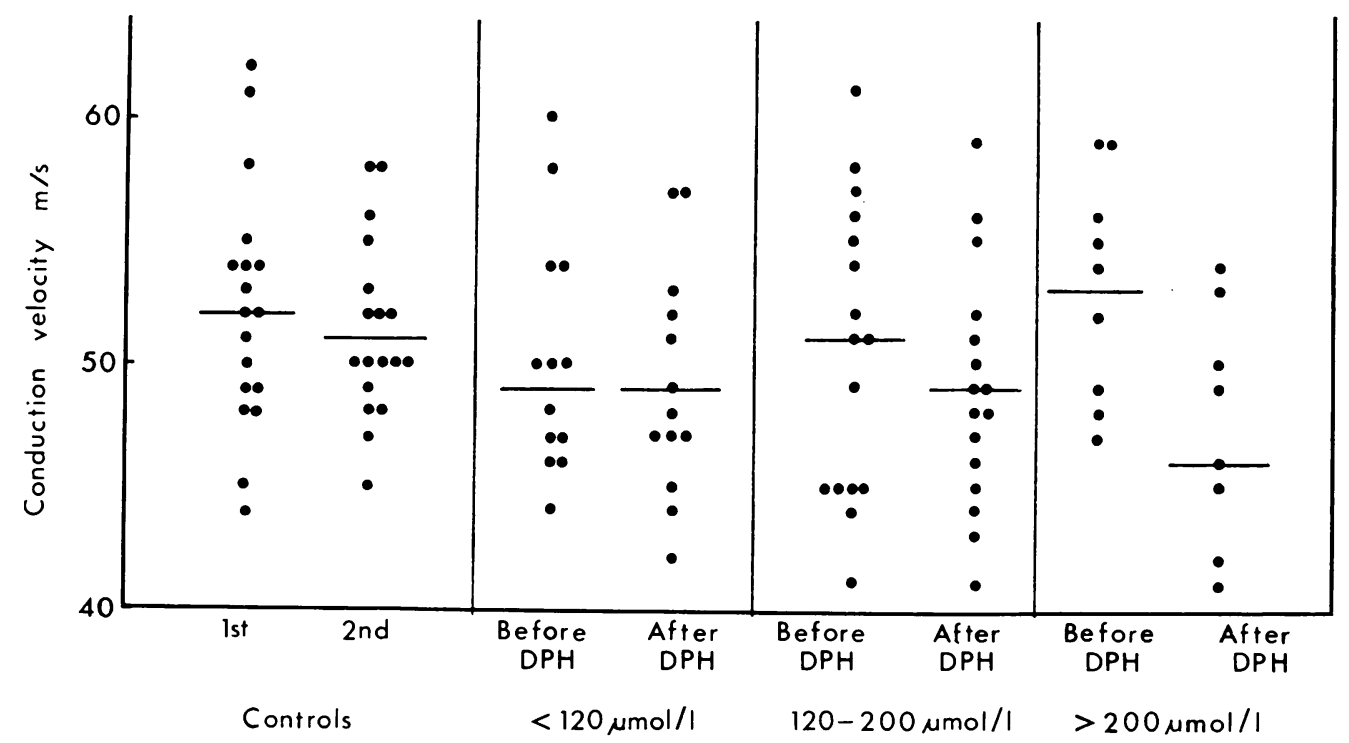

FIG. 1 Motor nerve conduction velocity showing two measurements in control animals, and measurements before and after dosing in three groups of animals which achieved different ranges of plasma DPH concentration. Bars indicate mean velocity for each group. 
T A B LE 2

COMPARISON OF INITIAL CONDUCTION VELOCITY WITH REPEAT VELOCITY MEASUREMENTS, PERCENTAGE CHANGE IN VELOCITY, AND STATISTICAL ANALYSIS OF RESULTS IN GROUPS OF ANIMALS WHICH ACHIEVED DIFFERENT RANGES OF PLASMA DPH CONCENTRATION

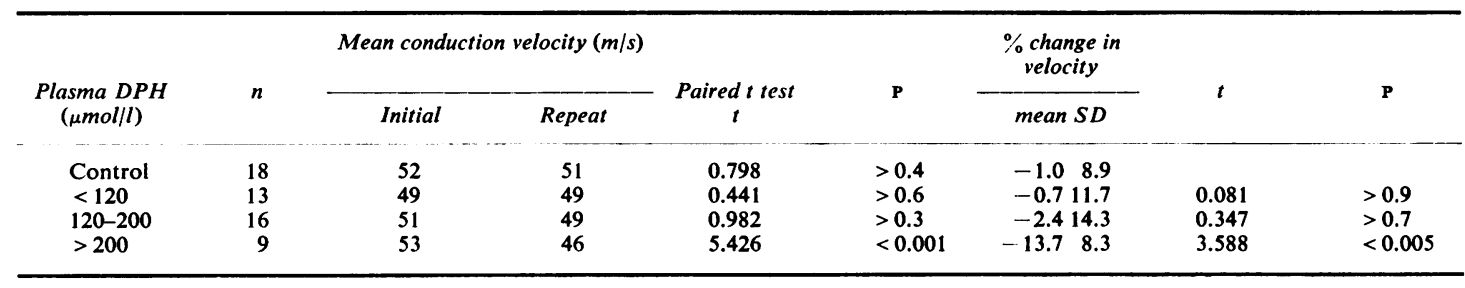

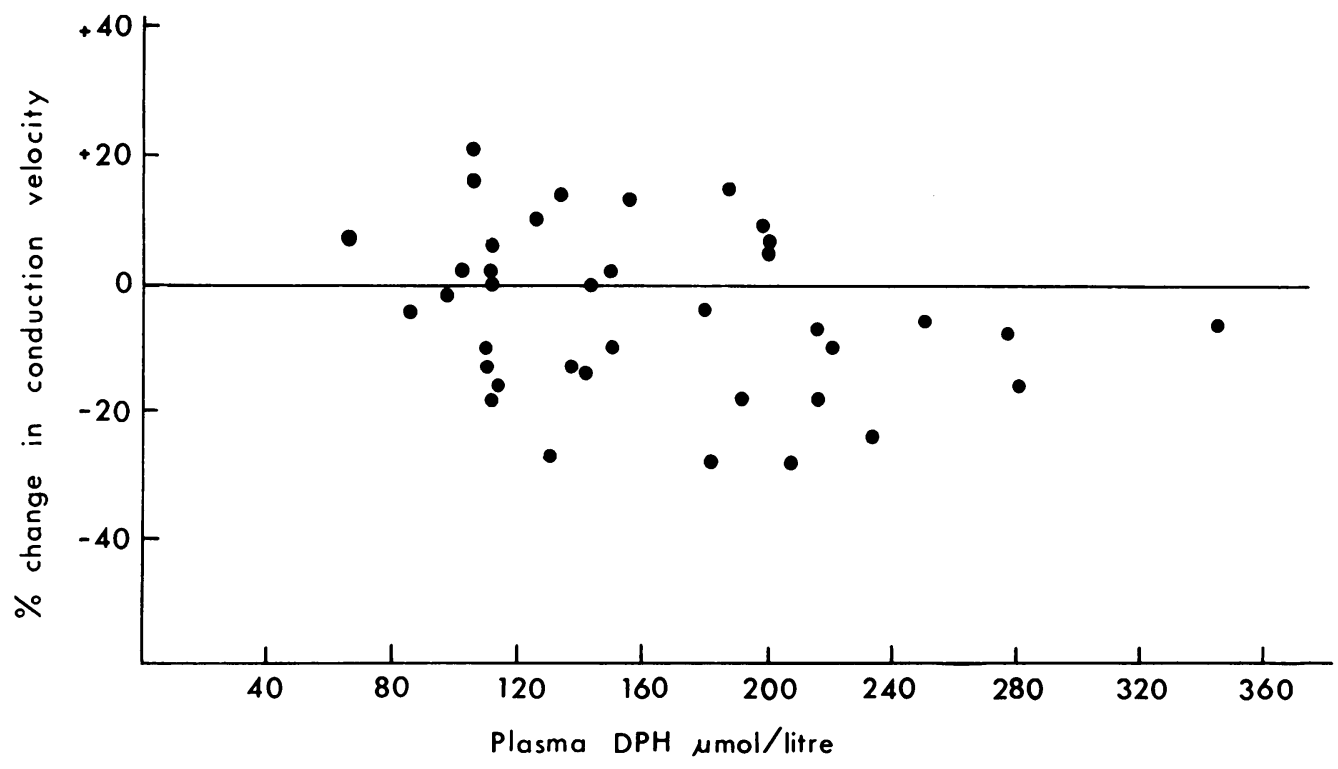

FIG. 2 Percentage change in conduction velocity shown in relation to plasma DPH concentration in intoxicated animals. 


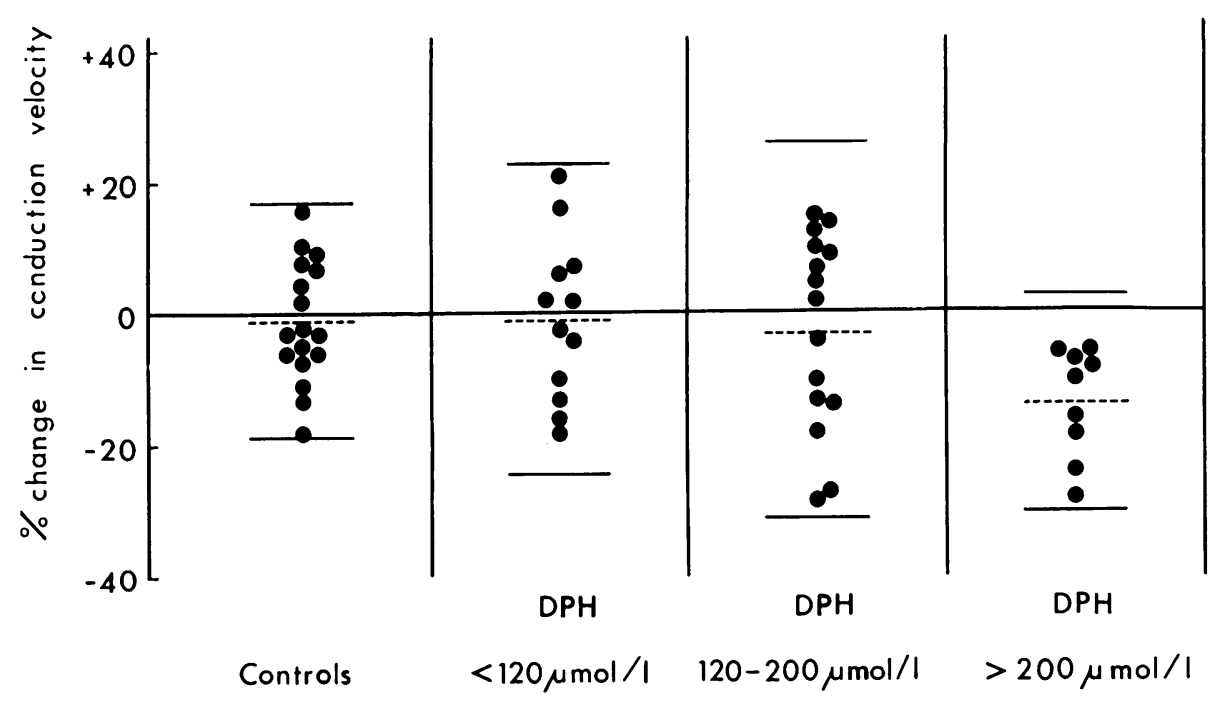

FIG. 3 Percentage change in conduction velocity between first and second estimations in control animals and in groups achieving different ranges of plasma DPH concentration. Dotted bar indicates mean and solid bars two standard deviations from mean.

again between one and three weeks later. Plasma DPH concentration had fallen to zero and velocity had increased in all. The percentage change, compared with the velocity when intoxicated, ranged from +13 to $+38 \%$ (mean $+22 \%$ ). The numbers are too small for statistical analysis, but in three of the four examined the increase was greater than for any control animals.

\section{DISCUSSION}

In the present study, results have shown that there is a reduction in peripheral nerve conduction velocity within a few days in guinea pigs in which plasma DPH concentration is greater than $200 \mu \mathrm{mol} / \mathrm{l}$. Plasma levels of this order are greater than those which appear to influence conduction velocity in man and at which toxic effects on the central nervous system are first evident in man. Birkett-Smith and Krogh (1971) demonstrated a reversible reduction of velocity in man when plasma levels were over 120 $\mu \mathrm{mol} / \mathrm{l}$ and Chokroverty and Sayeed (1975) found a reduction in a group of patients with plasma levels over $80 \mu \mathrm{mol} / \mathrm{l}$. In guinea-pigs this effect was not evident until levels over $200 \mu \mathrm{mol} / \mathrm{l}$ were achieved. When studying effects on the central nervous system in man, Kutt et al. (1964) found that nystagmus occurred when plasma levels were $15-30 \mu \mathrm{g} / \mathrm{ml}(60$ $120 \mu \mathrm{mol} / \mathrm{l})$, ataxia was evident at $30-40 \mu \mathrm{g} / \mathrm{ml} \mathrm{(120-}$
$160 \mu \mathrm{mol} / \mathrm{l})$, and above this level blurred vision, mental changes, and gross incoordination developed.

There are no available data about DPH metabolism in the guinea-pig. In rats, rabbits, and man there is evidence that the drug is cumulative and that the plasma level is maintained for longer at a constant level after repeated doses than after a single dose (Dill et al., 1956; Arnold and Gerber, 1970). It was therefore decided to measure conduction velocity in guinea-pigs after DPH had been administered for three or four days, although we cannot be sure that the plasma level was stable. However, blood samples were taken immediately after velocity was measured. It is known in general that the concentration of a drug at its site of action is in physicochemical equilibrium with the drug concentration in plasma. In other words, the plasma level is related to the pharmacological effect (Brodie, 1964). Thus, it is reasonable to correlate nerve conduction velocity with plasma drug level, and indeed a statistically significant correlation was found.

The mechanism responsible for the reduction in conduction velocity has not been elucidated. Velocity was reduced only in animals with high DPH levels which were clinically in a poor general condition. It might be suggested that the reduction in velocity was due to a general metabolic disturbance, possibly partly related to low food and water intake. However, velocity has been found to be unaffected in equally 
sick animals intoxicated with other substances (personal observations). Alternatively, the effect might be due to early changes in the development of a demyelinating or axonal neuropathy. Again, this seems unlikely because the change in conduction velocity occurs within a few days of exposure and limited observations suggest that the effect might be reversible within a short time.

It seems probable that the reduction in conduction velocity demonstrated in these experiments has a different cause from the chronic effect of long-term DPH administration. The acute effect appears to be reversible within a short time and is possibly due to a specific metabolic disturbance, whereas it seems likely that changes are longer lasting or permanent when they occur after treatment for many years. Further experiments are planned to investigate the time relation of change in velocity and exposure to DPH in more detail.

We are grateful to Dr P. T. Lascelles for his help with some of the DPH estimations and for his advice.

\section{REFERENCES}

Arnold, K., and Gerber, N. (1970). The rate of decline of diphenylhydantoin in human plasma. Clinical Pharmacology and Therapeutics, 11, 121-134.

Birkett-Smith, E., and Krogh, E. (1971). Motor nerve conduction velocity during diphenylhydantoin intoxication. Acta Neurologica Scandinavica, 47, 265-271.

Brodie, B. B. (1964). Symposium on clinical drug evaluation. Difficulties in extrapolating data on metabolism of drugs from animal to man. Clinical Pharmacology and Therapeutics, 3, 374-380.

Chokroverty, S., and Sayeed, Z. A. (1975). Motor nerve conduction study in patients on diphenylhydantoin therapy. Journal of Neurology, Neurosurgery, and Psychiatry, 38, 1235-1239.

DeCastro, J. H. X., Acosta, M. L., Sica, R. E. P., and Guereio, N. (1972). Sensory and motor nerve conduction velocity in long-term diphenylhydantoin therapy. Arquivos Neuro-Psiquitria (Sao Paulo), 30, 215-220.

Dill, W. A., Kazenko, A., Wolf, L. M., and Glazko, A. J(1956). Studies on 5, 5'-diphenylhydantoin (Dilantin) in animals and man. Journal of Pharmacology, 118, 270-279.
Eadie, M. J., and Tyrer, J. H. (1974). Hydantoin anticonvulsants. In Anticonvulsant Therapy, Pharmacological Basis and Practice. Chapter 5, p. 37. Churchill Livingston: Edinburgh.

Eisen, A. A., Woods, J. F., and Sherwin, A. L. (1974). Peripheral nerve function in long-term therapy with diphenylhydantoin. Neurology (Minneap.) 24, 411-417.

Encinoza, O. (1974). Nerve conduction velocity in patients on long-term diphenylhydantoin therapy. Epilepsia, 15, 147-154.

Fullerton, P. M. (1966). Chronic peripheral neuropathy produced by lead poisoning in guinea-pigs. Journal of Neuropathology and Experimental Neurology, 25, 214-236.

Goldberg, V. D., Rosewarne, C., and Lascelles, P. T. (1974). Analysis of anticonvulsant drugs in a routine service. Proceedings of the Society of Analytical Chemistry, 11, 288-290.

Hopf, H. C. (1968). Über die Veränderung der Leitfunktion peripherer motorischer Nervenfasern durch Diphenylhydantoin. Deutsche Zeitschrift fur unde Nervenheilk, 193, 41-56.

Kutt, H., Winters, W., Kokenge, R., and McDowell, F. (1964). Diphenylhydantoin metabolism, blood levels and toxicity. Archives of Neurology (Chic.), 11, 642-648.

Lovelace, R. E., and Horwitz, S. J. (1968). Peripheral neuropathy in long-term diphenylhydantoin therapy. Archives of Neurology (Chic.), 18, 69-77.

MacGee, J. (1970). Rapid determination of diphenylhydantoin in blood plasma by gas-liquid chromatography. Analytical Chemistry, 42,421-422.

Meijer, J. W. A., Meinardi, H., Gardener-Thorpe, C., and Vander Kleijn, E. (1973) (eds). The chemistry and technique of flash alkylation in gas chromatography. In Methods of Analysis of Antiepileptic Drugs, pp. 110-125. Excerpta Medica: Amsterdam.

Morrell, F., Bradley, W., and Ptashne, M. (1958). Effect of diphenylhydantoin on peripheral nerve. Neurology (Minneap.), 8, 140-144.

Toseland, P. A., Grove, J., and Berry, D. J. (1972). Isothermal GLC determination of the plasma levels of carbamazepine, diphenylhydantoin, phenobarbitone and primidone. Clinica Chimica Acta, 38, 321-328.

Vajda, F., Williams, F. M., Davidson, S., Falconer, M. A., and Breckenridge, A. (1974). Human brain, cerebrospinal fluid and plasma concentration of diphenylhydantoin and phenobarbital. Clinical Pharmacology and Therapeutics, 15, 597-603. 